\title{
A Simple Portable Cable Way for Agricultural Resource Collection
}

\author{
${ }^{1}$ Dr. Shankar Krishnapillai
}

\begin{abstract}
A signficant problem faced by the Indian farmer today is the difficulty of obtaining labor for farm operations. The most labor intensive operation is the post-harvest resource collection. A simple, economical, compact cable way system has been designed, developed and fabricated to haul sugarcane loads from the field. The cable way is made up of simple collapsible steel 'A' posts, which can be assembled on-site from ready-made frames. The sugarcane loads are slung on trolleys which move on a steel cable passing over the top of the frames, the cable being tightened with a chain pulley block. The trolleys are pulled along by a recirculating rope operated by a winch. The empty trolley is pulled along by the same rope along a cable way running near the bottom of the ' $\mathrm{A}$ ' post,. Several trolleys can move simultaneously along the cable way. With a 2 HP motor the trolley speed was noticed to be about $0.3 \mathrm{~m} / \mathrm{s}$ and the overall performance of the prototype was satisfactory. The entire setup is fabricated from easy available and low cost components.
\end{abstract}

Keywords: Cableway, Rural technology, Mechanization

\section{Introduction}

There are various problems faced by the Indian farmer in the $21^{\text {st }}$ century, chief among them is a critical shortage of manpower for all sorts of farming activities (Mahesh Ramachandran 2004). The typical Indian farm is small; hence large scale mechanization is not very feasible (Majumdar et.al 2001) and the crisis is severe. Lack of insufficient manpower is especially severe in the post-harvest period, when significant manpower is required to transport agricultural produce from the field to the 
collection point outside. Thus in recent times there are severe labor problems in the collection of agricultural resources and discourages the farming profession (Shama 2007). The aim of the cable way is to provide an economical and simple solution to this problem.

Cableway (or ropeway) systems are used for material handling or transportation of passengers. Cableways are particularly useful in rugged terrain and in environmentally sensitive areas. The cableway is possibly the most efficient of all modes of transport. The cableway technology is quite basic and it has many advantages which are presented by Dwyer (1975). First, it can cover steep, rugged and otherwise inaccessible ground. Being capable of moving goods in a straight line, it can easily reduce road haul distances by a sizeable factor. Another advantage of the cableway is its 'non-intrusive' nature i.e., minimal environmental impact. This is emphasized in the environmental assessment report of ropeway across Guwahati river in Assam State, India (Pollution Control Board, Assam 2009). The area requirements of cableway are minimum with a small cleared pathway under the posts, which are widely separated. The third advantage of the ropeway is the moderate energy consumption and minimum labor requirements (Wuschek 1982). Various cableway systems are discussed by Edward et.al (1985) which include mono-cableway and bi-cable way and their many variations. The bi-cable way system is adopted here, where the load moves along on a cable on rollers and is hauled by a moving rope clamped to the load. The current cable way system was implemented with an NGO for the benefit of sugarcane farmers in the Karur District in Tamilnadu State, India.

\section{Objectives of the Portable Cable Way}

After several discussions with the farmers and the feedback obtained thereof, it was decided that the cableway system and the steel posts must be portable and economical to fabricate and operate. The main components are (a) steel posts to carry the cableway(b) winch and motor unit and (c) chain pulley block and (d) steel cables and (e) recirculating rope. Several farmers could 
share the portable cable way. Given the budgetary constraints of the project, it was decided the prototype cableway could be fabricated and tested for $100 \mathrm{~m}$. This distance could be readily extended with more posts. It should be able to continuously haul several head loads of sugarcane (each $25 \mathrm{~kg}$ ) over this distance at a moderate speed; the speed could be readily increased with a more powerful winch motor. The components are cheap and economically purchased and fabricated.

\section{Description of Portable Cable Way}

Figure. 1 shows the photograph of the portable cable way in operation. It shows a typical cableway post made of easily available tubular steel pipes. The pipes are bent into two trapezium frames, which are hinged at the top and opened at the bottom and held thus with tie rods to form a sturdy ' $A$ ' shaped post when viewed transverse to the cable way (this assembly is shown in Figure.2). Also shown is a trolley (with sugarcane load in sling) fitted with two nylon wheels moving along the top cable, and also the recirculating rope which pulls it.

More technical details are shown in the next schematic diagram (Figure.3). There are many ' $A$ ' posts which are assembled on site from the portable frames. There are two end-posts which are especially sturdy, and a number of weaker intermediate posts (20 were used in the project). The ' $A$ ' post opens at an angle of about $40^{\circ}$ (see Figure.2) and is $2.3 \mathrm{~m}$ high with a base of $1.8 \mathrm{~m}$ (measured parallel to the cableway) and $1.78 \mathrm{~m}$ (transverse to cable way) forming a sturdy structure resistant to compressive and sidewise forces. The frames are held in place with tie rods (not shown in Figure.2). These tie-rods also support the bottom cable. Usually there is a spacing of about 5 to $7 \mathrm{~m}$ between two posts. 


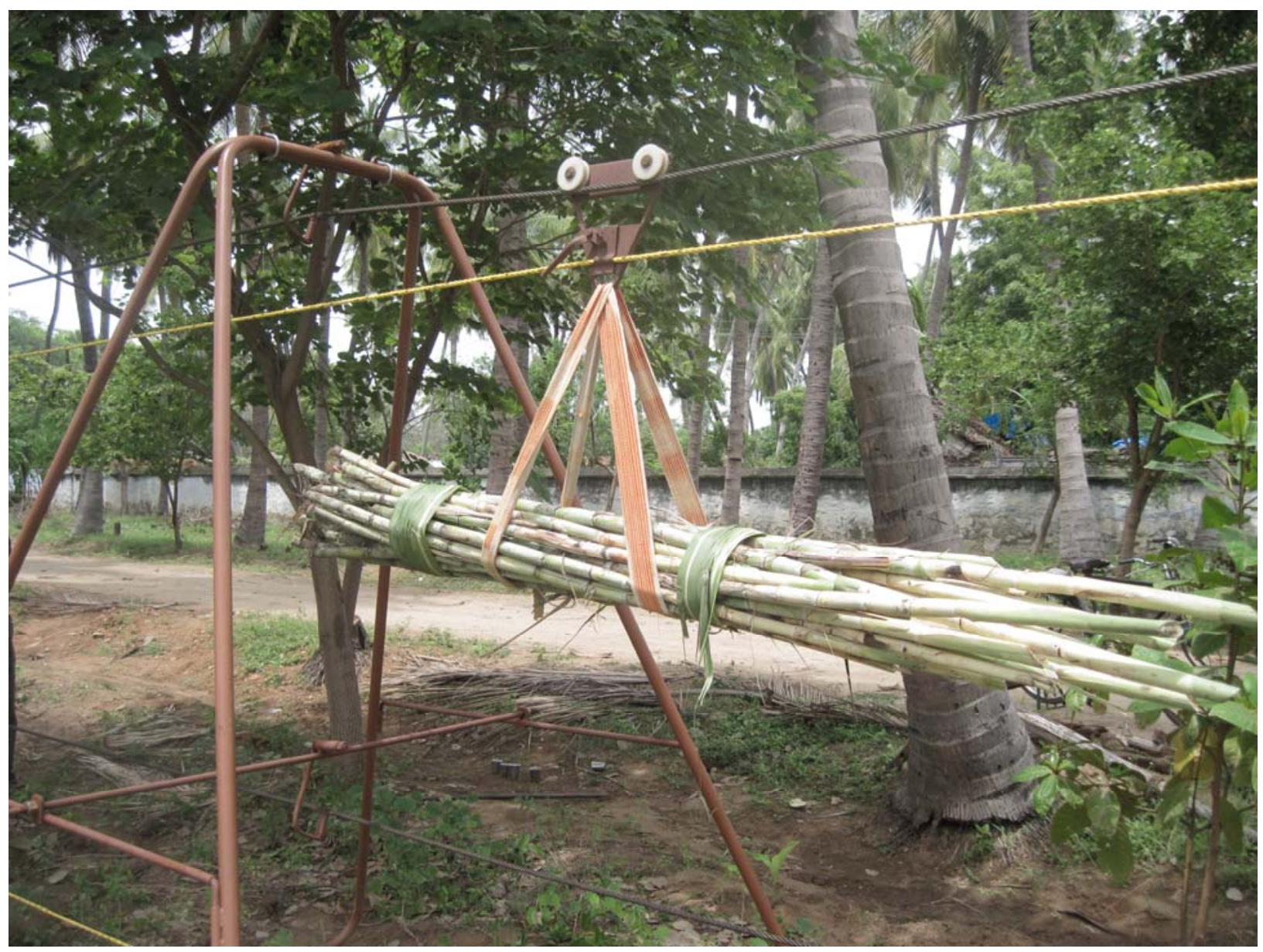

Figure.1 Photograph of portable cableway

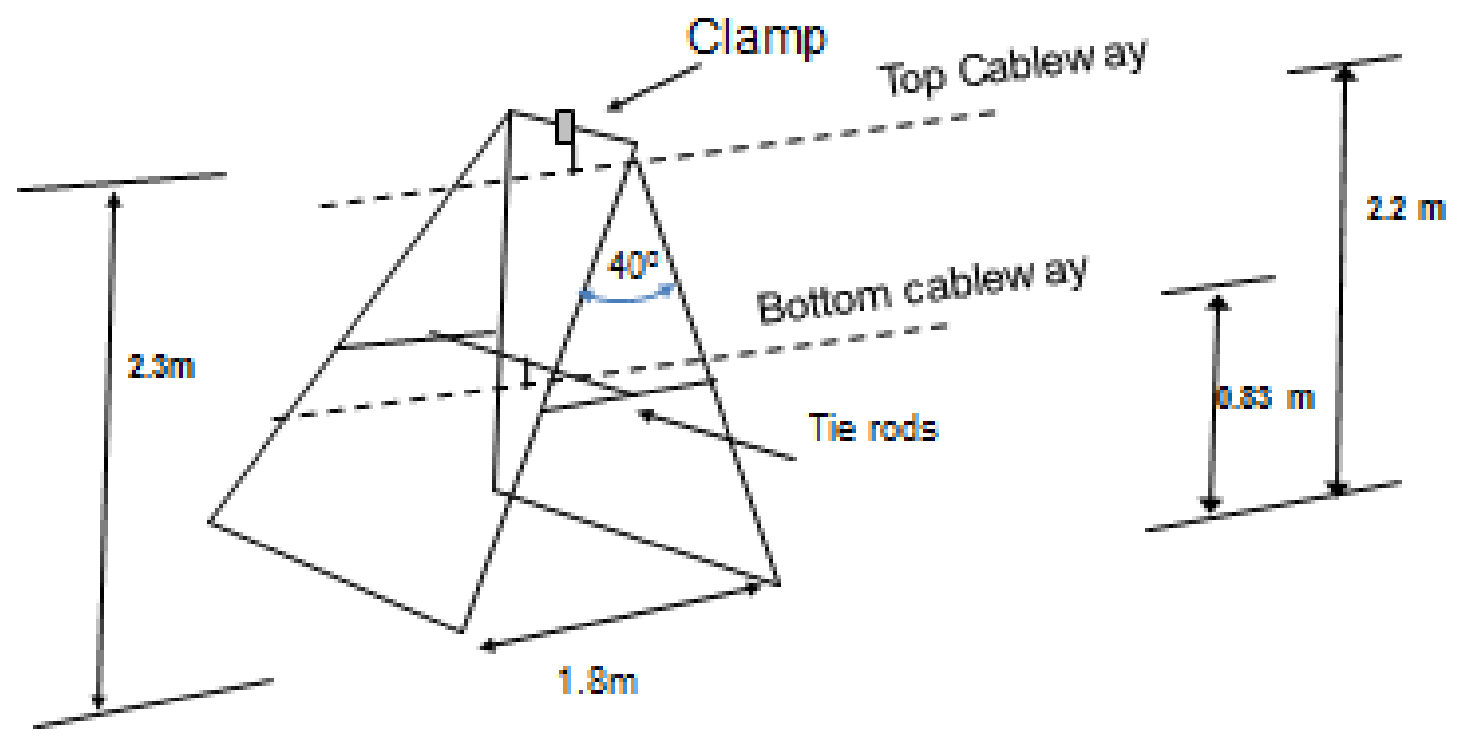

Figure.2 Assembly of a cableway post 


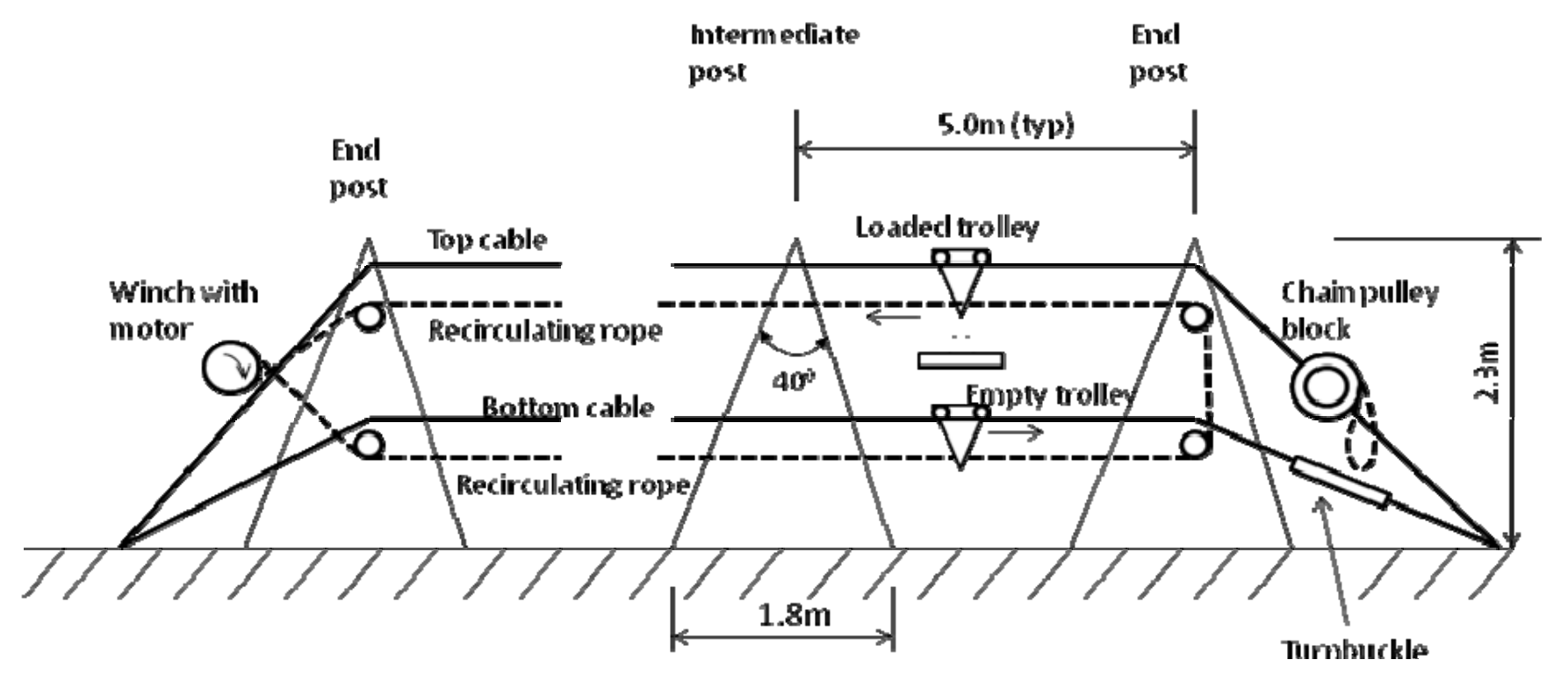

Figure.3 Schematic diagram of portable cable Way (dimensions in m) Not to scale

A $12 \mathrm{~mm}$ steel cable passes over the top of the posts. Both ends of this cable are buried $1.5 \mathrm{~m}$ in the ground and tightened with a 2 tonne chain pulley block. A recirculating rope provides the motive power to pull the loaded trolleys along the top cable and the unloaded trolleys along the bottom cableway (in opposite directions). This rope is wound round a winch drum driven by a 2HP motor; the loads moving at a walking speed. The upper cable is tightened using the chain pulley block. A turnbuckle suffices for the lower cable way which carries lighter loads (it is also possible to connect both cables to the chain pulley block, with a slight modification).

The cable tension when calculated for a single concentrated load of 50kg at mid-span for a permissible sag (Brockenbrough and Meritt 1999) of $3 \%$ of span (span being $7 \mathrm{~m}$ ) is $500 \mathrm{kgf}$. The downward compressive force on the end posts was $500 \mathrm{kgf}$ and in the intermediate posts was considerably smaller. Hence the end posts have large tubular cross sections (38mm OD, 2mm thick) and intermediate posts have smaller cross sections( $32 \mathrm{~mm}$ and $2 \mathrm{~mm}$ ). The diameter of the cable was finalized as $12 \mathrm{~mm}$ (7 tonne breaking capacity) because it has to be sufficiently broad for the trolley wheels to roll on. 
Figure. 4 shows a photograph of the chain pulley block, usually used for hoisting loads, now adapted to tightening the cable. It is capable of considerable mechanical advantage in lifting heavy objects. The 'hook' end of the device, which is normally connected to the load to be hoisted is now attached to the end of the cable coming from an end post. The other end of the chain (normally attached to the roof beam) is wrapped on a concrete block and buried about $1.5 \mathrm{~m}$ under the ground. By pulling the side loop chain, the operator tightens the cable with ease. Thus by using a simple chain pulley block, tightening is accomplished without recourse to more expensive hydraulic and pneumatic devices usually seen in cableways.

Figure.5 shows the photograph of the winch with 2 HP motor with a rated speed of $1500 \mathrm{rpm}$. A reduction gear box of ratio $1: 5$ is used to connect the motor to the winch drum. The drum is about $0.34 \mathrm{~m}$ in diameter with a corrugated surface for better grip. An $8 \mathrm{~mm}$ diameter nylon rope made endless is wrapped around on the the drum. This rope (see Figure.3) pulls both the top and bottom trolleys in opposite directions.

Among the other components of less significance is the trolley in the photograph (Figure.1) which is made of a triangular steel plate (with about $0.18 \mathrm{~m}$ sides). Two nylon rollers attached to this plate roll over the $12 \mathrm{~mm}$ diameter cable. The trolley can be clamped or unclamped to the recirculating rope. There is a simple sling to put the sugarcane load. Once the loaded trolley reaches the destination, it is unclamped from the recirculating rope and put on the lower cable way and again clamped to the rope. When the cable way is in operation, upto five loaded trolleys were simultaneously hauled before deterioration of speed and performance took place. 


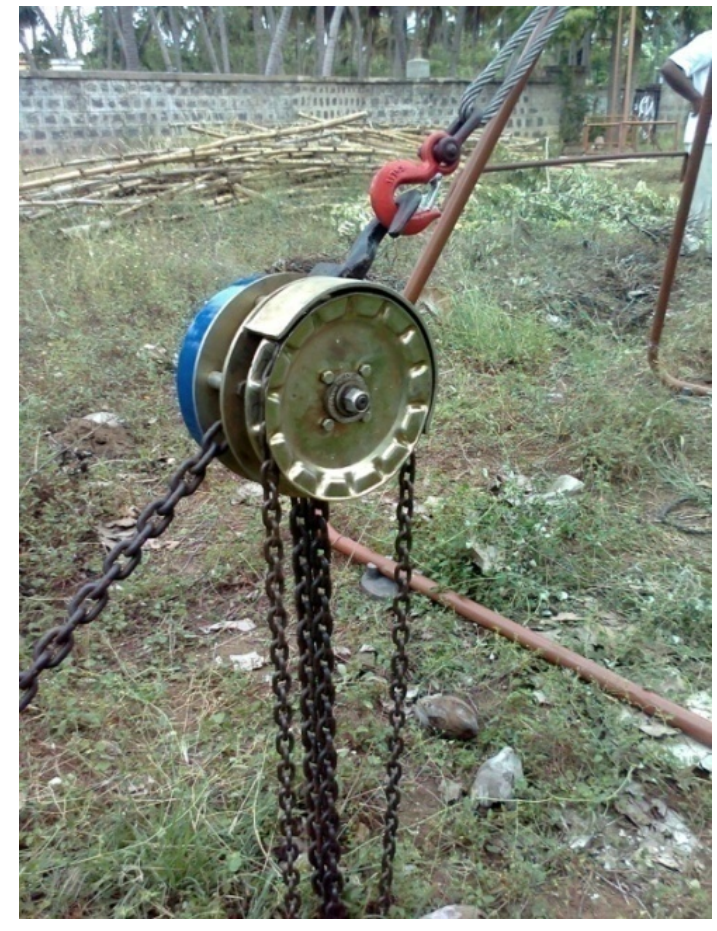

Figure.4 Chain pulley block

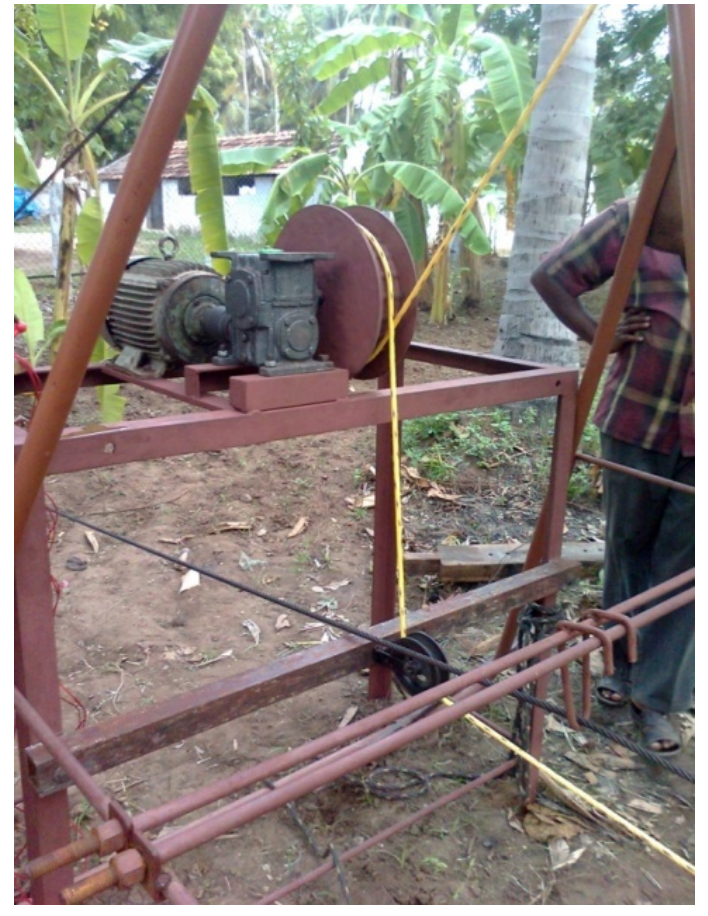

Figure.5 Winch with 2 H.P motor

\section{Economy and Labor}

The total cost of cableway fabrication (including 20 posts and one 2kVA generator) was Indian Rupees 2,00,000 (USD 4,000). The intention is that the device can be shared by many farmers. There is also the convenience whereby the farmer need not wait for days to find dozens of laborers for manual work. Farmers do not opt for a permanent cable way since such facilities are needed for only about ten to fifteen days in a year. For the erection of portable cableway, it is sufficient to engage four laborers for half day. Increasing the length of the cable way requires less than proportional increase of labor, since it is only required to insert extra posts - the effort for installing winch and pulley block is same irrespective of the length of cable way. The number of workmen and time required for transportation increase with obstacles such as small trenches, furrows, water ways, irregular surface and also the weather. With the portable cable way such obstacles do not matter once the cable way is erected and in continuous operation. In a cable way of the current design only four laborers are required to continuously operate the cableway irrespective 
of its length (two persons at each end) and the effort required of them is less harsh than headload operations.

\section{Conclusions}

A simple, economical, compact portable cableway has been developed, fabricated and tested for transportation of sugarcane loads from farm to collection point. The cable is tightened by a chain pulley block. Using the concept of recirculating rope, and by means of upper and lower cable ways contained in the post, there is provision for two way travel of trolleys (loaded and unloaded). Within the budget constraints of the project, the prototype cableway has been tested for a distance of $100 \mathrm{~m}$ and works well. There are significant economies in labor charges by using this device.

\section{References}

Dwyer, C. F. 1975, Aerial Tramways, Ski Lifts, and Tows, Forest Service, U.S. Dept. of Agriculture.

Edward S Neumann, Sam Bonasso, Abel D.I.Dede 1985, Modern Material Ropeway Capabilities and Characteristics, Journal of Transportation Eng, 111,651-653

Mahesh Ramachandran 2004 Labor Mobility and Paradox of Rural Unemployment - Farm Labor Shortage: A Micro Level Study,,Indian Journal of Labor Economics, 47(1), 25-37

Majumdar, A., Karmakar, S. and Gupta, J.P. 2000. Status of Farm Mechanization in Bihar, India. Journal of Interacademicia. 4(4),21-30

Roger L Brockenbrough, Frederick S. Merritt, 1999, Structural Steel Designers Handbook $3^{\text {rd }}$ Ed.”,McGraw Hill

Sharma, A 2007, The Changing Agricultural Demography of India: Evidences from a Rural Youth Perception Survey. International Journal of Rural Management, 3(1),27-41

State Pollution Control Board (Assam) 2009, Environmental Impact Assessment Report-, Guwahati Ropeway Project, Assam, India

Wuschek, M. 1982, Ropeways-Economical and Energy-Saving, Internationale Seilbahn-Rundschau Journal, 3, 118-222 